\title{
Brief discussion of Distributed Photovoltaic Grid-Connected Interface Device
}

\author{
Wang Shandan ${ }^{\mathrm{a}}$, Yang Guosheng ${ }^{\mathrm{b}}$ \\ China Electric Power Research Institute, Beijing 100192, China \\ aemail:648265377@qq.com, bemail:yangguosheng@epri.sgcc.com.cn
}

KEYWORDS: distributed PV; interface device; Smart grid

\begin{abstract}
This paper mainly studies the distributed PV interface device how to realize the control of distributed power grid, and the interface to achieve the function of islanding prevention, the integration of relay protection, measurement and control, power quality control, remote control, harmonic control functions to achieve unified management. It can be used to connect the distributed photovoltaic power generation system and the grid, to achieve unified management of distributed $\mathrm{PV}$, to solve the problems of large harmonic generation in distributed generation units at low power operation without any impact on the function of power grid.
\end{abstract}

\section{Introduction}

In recent years, distributed photovoltaic power generation has been widely used in industrial plants, public buildings, residential buildings and the construction ground by taking advantage of small capacity, low access voltage level, near load side and flexible configuration. As an important application of solar power, distributed photovoltaic power generation has wide application prospect by making full use of the characteristics of a wide range of solar radiation, avoiding the limitation of concentration of site construction, especially flexible for the high population residential density in the Middle East of China.

From the existing experience of photovoltaic power generation operation, distributed photovoltaic power generation still has many problems to solve due to its own characteristics, the different access methods, the low access voltage, the complex operation mode and etc. Coupled with the imperfect relevant policies, unstandardized management, and unqualified standard, the safety and stability operation of power grid is threatened by the hidden danger. There are still many blockings in distributed photovoltaic power generation access network, which prevent it from playing full role of its advantages of small scale, high efficiency and good benefit.

In 2013, the State Grid Corp of China worked out the preparation of the "distributed photovoltaic power generation network interface device technical specifications", this enterprise standard made the basic requirement to the function, performance, safety, electromagnetic compatibility and test of the distributed photovoltaic power generation grid connected interface device. But it's relatively simple. The function is not perfect and just to put forward requirements to the 10KV level of the device [1]. Through the research of distributed PV grid connected flexible interface device, the measurement, power quality acquisition, relay protection, voltage regulation, power flow control, harmonic detection and control methods of distributed photovoltaic power generation access distribution network are studied and developed. Research and development of practical, technical and converged network interface devices, to solve practical difficult problems of distributed PV power connected to the grid.

\section{Main Research Contents}

To solve the key technical problems, to carry out related research around the collection measurement, power quality control, protection, measurement and control, monitoring, and the process of the practicality of the communication integration and network interface equipment. The specific research contents are as follows [2]. 


\section{Research on the Whole Scheme of Grid Connected Interface Equipment}

According to the demand analysis of grid connected interface equipment, the configuration scheme of grid connected interface equipment in distributed photovoltaic power generation is defined, and the overall scheme of grid connected interface equipment is formulated.

To study the internal and external communication mode of distributed photovoltaic power generation system with different capacity scale and different voltage level, to determine the best communication scheme and model, which provides the basis and guidance for the communication function and module design of the grid connected interface equipment [3]. To focus on communication and wireless communication program and the implementation between the system and the distribution network scheduling system. And finally the integrated scheme of the integrated network interface device is determined, which is the integration of measurement, power quality collection, protection, measurement and control, communication and monitoring.

\section{Research on Harmonic Control Algorithm and Control Module Chassis Operation Mode}

In the current distributed photovoltaic power generation, in the morning, evening or less light, distributed photovoltaic grid connected inverter output power is low, the output current is small and causes the multiply of the harmonic of the output of the inverter, Lead to the distributed PV power in the region where harmonics exceed the standard, seriously affect the power quality and load of the normal work.

In order to solve this problem, raises the group control of harmonic elimination control strategy of the network interface device master chassis and control module based on coordinated operation mode. The control module and the main control module are used to coordinate the work of the main control module and the function of real-time adjustment to reduce the effective value and percentage of the harmonic and improve the power quality [4].

\section{Development and Experimental Verification of Grid Connected Interface Equipment}

Based on the function module of the grid connected interface equipment, the system layout of each module of the grid connected interface equipment is optimized and the research on the configuration, size and installation methods of the grid connected interface equipment which is suitable for different user needs, enhance the practical performance of the grid connected interface equipment. The design and research of the internal structure, production technology, electromagnetic compatibility and other aspects of the grid connected interface equipment are also carried out. Enhance the adaptability of the products and the environment of the grid connected interface equipment, and finally carry out the relevant type test.

\section{Basic Research and Existing Support Engineering Project}

Departments have developed a general control system protection platform (UP platform), thus, it lays the solid foundation for the two board design, EtherCAT and Ethernet communication and other aspects, as well as providing a good support for the development of equipment and hardware. In the research of the inverter, we have developed $2.5 \mathrm{KW} \sim 500 \mathrm{kw}$ various power series inverter, gotten the golden sun certification, accumulated a wealth of experience in power electronic topology design, a hardware design and structure design. In terms of energy storage equipment, the energy storage controller, BMS, high power interleaved parallel connected energy storage DC/DC converter is developed and used in the practical engineering [5].

\section{Harmonic Elimination Control}

This product creatively put forward the method of main control plus control to solve the problem of large harmonic percentage of distributed photovoltaic power generation equipment in low power 
operation. When the inverter is in low power, the sampling precision is low, and it can produce large harmonics. By increasing the output current, the effective value and the percentage of the current harmonic can be reduced.

Control module constantly detects the various distributed generation units and outlets of harmonic voltage and current, circuit breaker status, active reactive power and sent to the main control module. According to send data and outlets and each generation unit harmonic information, it calculates and issued instructions to each inverter, improves the reactive power, increases the output current of the inverter, and effectively reduces the distributed photovoltaic inverter output harmonic percentage, hitting the goal of controlling eliminating harmonic [6]. When the active power is increased, the reactive power output is decreased, and the active power output is improved.

In this way, it can not only guarantee the power of distributed PV grid connected inverter, but also can reduce the harmonics and improve the power quality. At the same time, the main control cabinet is reserved for the communication interface with the APF equipment, which can improve the ability of eliminating harmonic by controlling the APF. The sub control module as an independent part, users can decide whether choose or not choose according to their own needs.

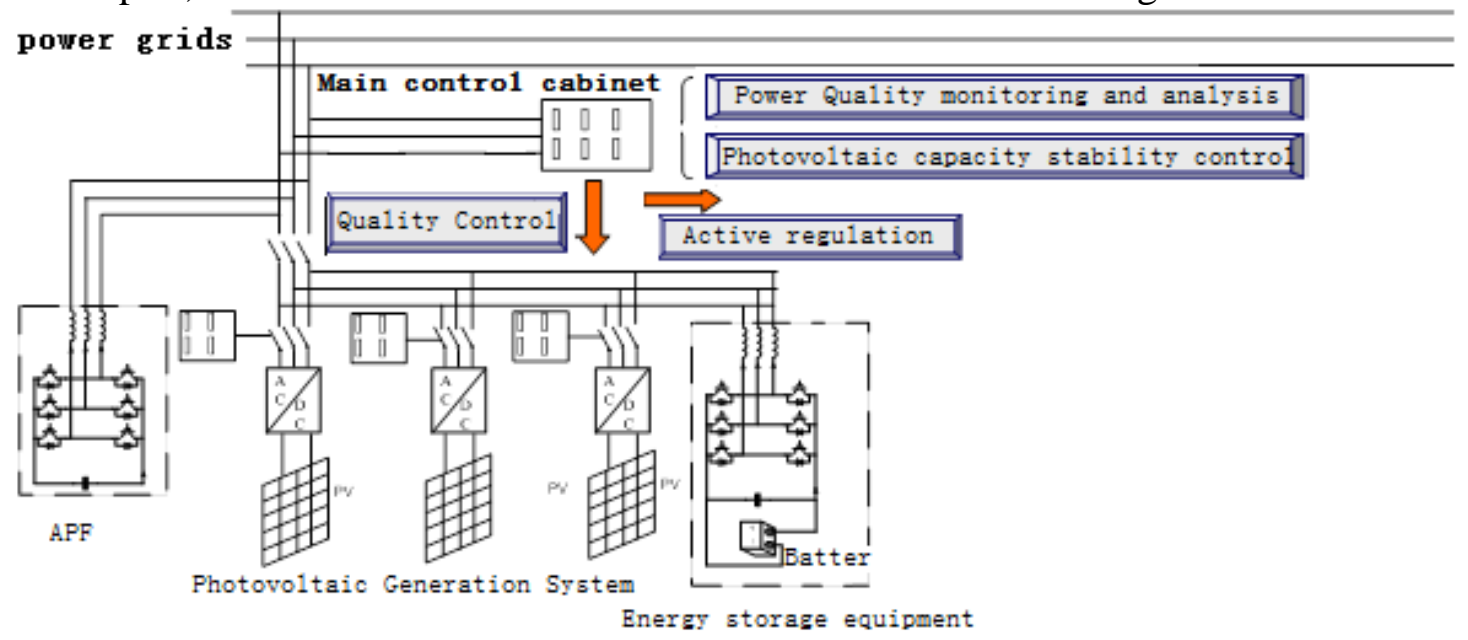

Fig. 1 Control of harmonic elimination

\section{Isolated Island Control}

There are dead zones in the existing inverter stage, both passive and active [7]. In the case of isolated island, the $100 \%$ cannot be disconnected from the grid. This product will be used as the backup protection of the inverter island protection. Through advanced control strategy, it can guarantee the disconnection of power grid and distributed power within 2 seconds.

\section{Relay Protection Technology}

Distributed relay protection function is different from the traditional relay protection function, on the basis of the existing traditional protection, it uses the joint development method to develop distributed photovoltaic system of relay protection control.

\section{Active/Reactive Power Regulation Technology}

For the $10 \mathrm{KV}$ voltage level of distributed photovoltaic power generation, the active / reactive power output of the distributed generation units is controlled, according to the power grid dispatching mechanism commands. For the $380 \mathrm{~V}$ level, the active / reactive power output of the distributed generation units is controlled according to the situation of the network voltage and current situation of the network and the user's setting. 


\section{Control of Harmonic Elimination Technique}

Achievement of the group control harmonic elimination algorithm is the innovation and technical difficulties of this products. Through the combination of power regulation and centralized harmonic compensation, the distributed photovoltaic power generation in the grid connected side and the load side of the harmonic come up to the standard[8].

\section{Conclusion}

In the aspect of domestic similar products design, NARI Group and XJ group has developed prototy pe grid interface, conduced a demonstration application, but it has no market application yet.

The network interface equipment of the two companies are mainly focused on 380V user side and 1 $0 \mathrm{kV}$ user side, with the basic functions like measurement, power quality detection, protection, contr ol and communication etc. However, there are function defects in harmonic detection, govern and is land protection of distributed photovoltaic power generation.

Although the product's market pattern has not yet formed, our company has a certain basis in dist ributed photovoltaic power generation equipment study, at the same time, creatively proposed the $\mathrm{m}$ ain control chassis + sub control module mode, to solve the low power operation of distributed gene ration unit problems and to implement

the function of preventing isolated island at the interface, enriches the product function based on the price of similar products. It will produce considerable economic benefits if the grid connected inter face equipment can get into the market quickly.

\section{References}

[1] The provisions of the distributed power access grid technology, enterprise standards of China State Grid Corp,Q/GDW480-2010

[2] ZHU Lin, SHI Dong-yuan, DUAN Xian-zhong. Standard function blocks for flexible IED in IEC 61850-based substation automation[J]. IEEE Trans on Power Delivery,2011, 26(2): 1101-1110.

[3] TAN Wen-shu. An introduction to substation communication network and system-IEC61850[J] .Power system technology, 2001, 25(9):8-9.

[4] Dmitry Ishchenko, Member, IEEE, Alexandre Oudalov, and James Stoupis, Member, IEEE, Protection Coordination in Active Distribution Grids with IEC 61850[C]. Transmission and Distribution Conference and Exposition (T\&D), 2012 IEEE PES, Orlando, FL, 7-10 May 2012: 1-6.

[5] Taha Selim Ustun, Cagil Ozansoy, and Aladin Zayegh. Modeling of a Centralized Microgrid Protection System and Distributed Energy Resources According to IEC61850-7-420[J]. Power Systems, IEEE Transactions on, 2012, 27(3):1560-1567.

[6] Taha Selim Ustun, Cagil Ozansoy, Aladin Zayegh, Simulation of Communication Infrastructure of a Centralized Microgrid Protection System Based on IEC61850-7-420[C]. Smart Grid Communications (SmartGridComm), 2012 IEEE Third International Conference on, Tainan, 5-8 Nov. 2012:492-497.

[7] HUANG Kai, ZHONG Qing. Interconnection inverter controller of distributed generations based on IEC61850[J]. Power System Protection and Control,2013, 41(6):123-127.

[8] LUO Si-bei, HUANG Run-chang, CUI Qi, et al. IED modeling based on object-oriented technology of IEC61850 standard[J]. Power System Protection and Control, 2009, 37(17): 88-92. 